Jaundice. This is followed by Dr. Edward F. Wells on Diabetes, who points out that glycosuria and diabetes are not synonymous terms. The different tests for sugar in the urine that he has found most satisfactory are Haines's test, the phenylhydrazine, Rubner's, the fermentation, Purdy's, Legal's, Gerhardt's, and the polariscope tests. All are succinctly described. The article concludes with the diagnosis, prognosis, and treatment of the disease. The author describes various diets-viz., the diagnostic, a strict routine, and a moderate routine diet. For coma, when it has developed, he recommends bleeding the patient to from 24 to 32 ounces, then introducing intravenously an equal amount of a 2 per cent. solution of bicarbonate of soda in normal salt solution, and repeating this in a few hours.

In the section on Surgery we find a full and complete article on Congenital Idiopathic Dilatation of the Colon, by Mr. P. L. Daniel, and on Surgical Pneumothorax as a Treatment for Phthisis, by Dr. F. Dumarest. Next to these comes an excellent résumé of the present status of the Cammidge Reaction by Dr. Edward H. Goodman, who presents us with a compilation of recent work along clinical, chemical, and experimental lines. As the result of his review of the subject Dr. Goodman concludes, amongst other points, that the clinical value of the reaction seems assured, that it is almost constantly associated with lesions of the pancreas, and that, although the test is not pathognomonic, yet, taken in connexion with the clinical history and other laboratory findings, it is strongly suggestive of pancreatic disease.

Dr. H. Schwatt follows with an article on the Treatment of Abscess in Hip Disease, with a report of cases, in which he details the general consideration of the question of infection with pyogenic organisms. With regard to the question of prompt evacuation as soon as a tuberculous abscess becomes palpable, he thinks that there is no rational explana,tion of any advantages to be derived from indiscriminate operative interference, and that the procedure must be considered as unsound and dangerous for the following reasons : a considerable number of these abscesses remain quiescent and become aborted; retention of the caseous material does not impede the progress of repair, nor does evacuation of pus promote the progress to recovery; and the sterile abscess does not constitute a grave danger in well-managed cases. He regards absolute non-interference as a more rational mode of procedure than indiscriminate operation, although the former is by no means applicable to all cases. The various methods of operation where this is carried out are described, and then this exhaustive paper concludes with a summary of cases. This article will well repay perusal.

The other departments of medical science and practice receive their due acknowledgment, and the volume concludes with an excellent chapter on the Pathogenesis of Spontaneous Cerebral Hæmorrhage, by Dr. A. G. Ellis.

Text-book of Discases of the Nose, Throat, and Ear, for the Use of Students and General Practitioners. By F. R. PACKARD, M.D., Professor of Diseases of the Nose, Philadelphia Polyclinic Hospital and College, \&c. London and Philadelphia: J. B. Lippincott. 1909. Pp. 369. Price 15s.

THE first chapter of this useful work is devoted to the methods of examination of the nose, throat, and ear, and the next to the application of remedies to diseased conditions. Under the former we have a brief dissertation on tuning-fork reactions, consisting chiefly of descriptions of well-known tests. The advice that in introducing a laryngeal mirror it should be carried back until its "tip is beyond the uvula" seems a little difficult to comprehend. The warning that unless care be taken when using hydrogen peroxide in suppurative otitis media some purulent material may be driven into the mastoid cells is possibly called for, but certainly some indication should be given as to suggested precautions. The description of the anatomy of the parts contains some interesting matter; but the note that the anastomosis between the veins in the anterior part of the nose and those of the integument affords the explanation of the redness of the nose seen in congestive disorders of the nasal chambers should have been placed under diseases of the nose. The cricoid is spoken of as the keystone of the larynx, whereas a keystone is only found in an arch. Under diseases of the nasal mucosa atrophic rhinitis is spoken of as an inflammatory disease, and we are told that when aural trouble is associated with it the outcome is occlusion of the tubes, the "result of nasal obstruction," a condition not frequent in atrophic rhinitis, to say the least of it. While it is easy to make critical remarks on details we see that when the author has spent a little time in correcting the minor errors, which are so freely scattered through this book, he will render it a useful guide to the post-graduate; at present it misses this object, possibly on account of the want of a friendly proof reader and a little rigid editing from the author.

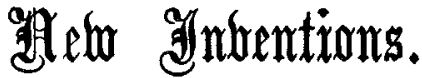

\section{AN ILLUMINATING MOUTH GAG.}

Two difficulties with which the surgeon may have to contend when operating inside the mouth are the want of space and light. The first of these is obviated by Hewitt's ingenious device of carrying the chloroform tubes along the

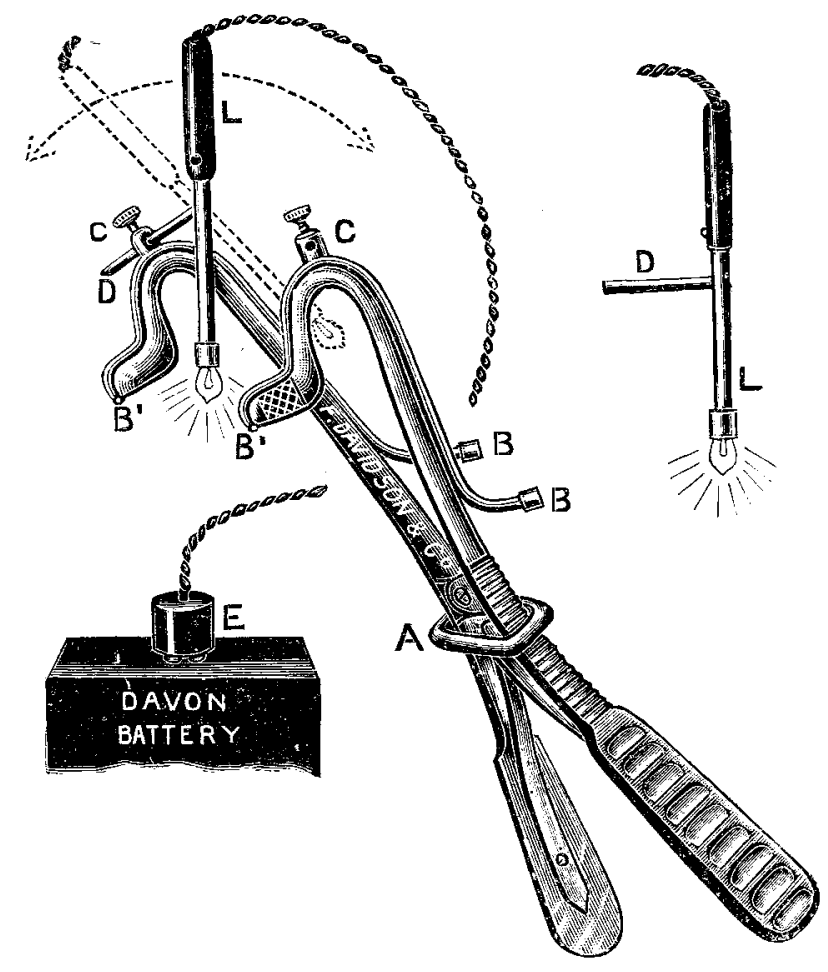

Hewitt's mouth gag with electric light. A, Moveable ring for fxing arms of gag. $B$ B. Tubes for conveying chloroform into the mouth. ${ }^{\prime} \mathrm{B}^{\prime}$, Openings of chloroform tubes inside the mouth. C C, Sockets with clamping screws, into either of which the rod $D$ can be placed, so that the light $I$ can be turned either to the right or left. E, Connexion to Davidson's Davon Battery.

arms of the gag, so that a separate tube for the anæsthetic is not required, and the surgeon can therefore have all the space inside the mouth to himself. To overcome the second difficulty I have had attached to Hewitt's gag (which not only by virtue of its chloroform tubes, but in other respects, 
I consider to be the best of all mouth gags) a little electric light. This is so arranged that it can be fitted to either arm of the gag and turned to the right or left side as required, and it enables the surgeon to get a good view of the whole of the inside of the mouth. The light is supplied by the "Davon" battery, which is an extremely handy and portable form of battery, and which lasts about ten hours. Being removeable it enables the whole of the gag to be sterilised by boiling. The accompanying illustration shows the main features of the gag as thus modified, and I need only add that Messrs. Davidson and Co., of 29, Great Portland-street, W., having taken the greatest pains, have been most successful in carrying out all the suggestions I have made to them in regard to it.

Wimpole-street, $\mathrm{W}$.

Cecil H. Leaf, F.R.C.S. Eng.

\section{A RUBBER CUP PESSARY.}

THE figure illustrates a very useful pessary, a rubber cup with vulcanite stem which Messis. Allen and Hanburys have made for me. It is more easily introduced than the vulcanite cup and it gives more to the movements of the

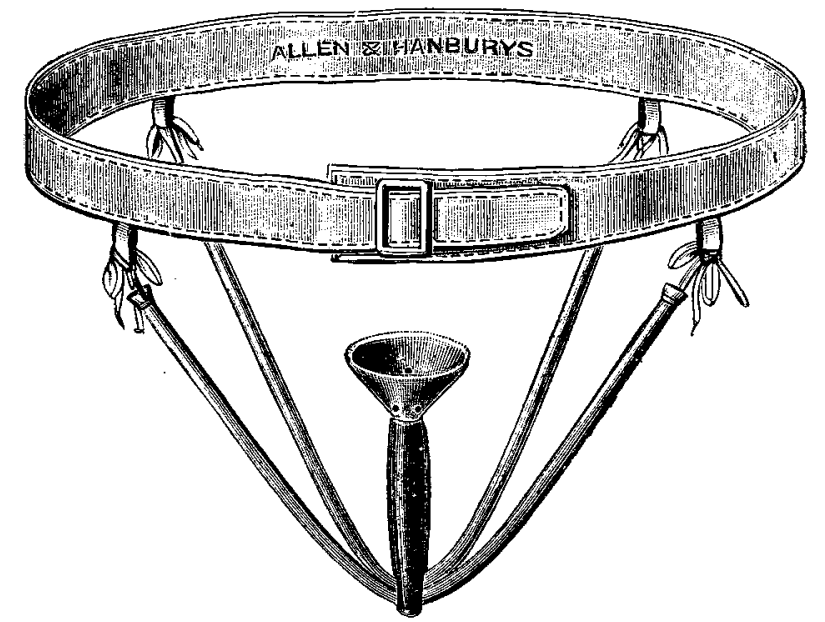

body. The all-rubber instruments are apt to double up with a heavy uterus. I have used these pessaries for some years and have found them most satisfactory.

J. H. Dudgeon, L.R.C.P. \& S. Edin.,

Honorary Surgeon, Workington Infirmary, Cumberland.

\section{Dooking JBack.}

\section{FROM}

THE LANCET, SATURDAY, Feb. 11th, 1832.

WESTMINSTER MEDICAL SOCIETY.

Saturday, February 4, 1832.

Dr. SIGMOND in the Chair.

\section{CLASTIC ANATOMY.}

PROPOSALS TO TEACH ANATOMY BY MIEANS OF SOLID PIECES CAPABLE OF BEING MOUNTED AND DISMOUNTED.

THE attendance at this Society is very variable, sometimes flagging for two or three successive evenings, when the room of meeting again becomes crowiled with members and visitors. The assemblage to-night was very numerous : the "Anatomy Petitions" lay on the table for signature, and might have been the cause of attraction. Whatever was the reason, however, few could have departed displeased with the evening's recreation. On entering the room we found preparations making for displaying to the Society a work of art, the ingenious inventor and constructor of which, Dr. Auzoux, was present. This work of art was an ARTIFICIAL
HUMAN BODY, which being now brought forward and placed upon its frame, attracted the eager attention of those present.

Mr. Costello, as a friend of Dr. Auzonx, introduced the "subject" with some appropriate remarks.

Amongst the many scientific gentlemen whose minds had been directed to the furtherance of anatomical studies by the construction of artificial bodies, Dr. Auzoux was one who from his youth had seriously entertained the design, which was now brought to so satisfactory a conclusion. It was a singular fact, that the original accomplishers of two grand features in modern surgical improvement, Dr. Auzoux and M. Civiale, were fellow-students, intimate friends, each of whom, however, looked upon the other's peculiar scientific penchant as an illusion incapable of realization. After many years of laborious trials and patient investigation, and after presenting to the world two or three specimens, Dr. Auzoux had at length produced the present, which was so accurate in its bearings, and so comprehensive in its details, as to render it of the utmost value to the student and the practitioner, and deserving the attention of the legislature, especially at a time when the question of anatomical study was beset with so many difficulties.

Dr. Auzoux has taken for his model the frame of an athletic man of tolerable height, the muscles being fully and beautifully developed. The position is well chosen, and, the feet being fixed firmly on a wooden frame work, admits of the manipulation requisite for the study of the figure. The integuments are absent, and the first layer of muscles is exposed to view as if cleanly dissected for a "demonstra. tion." These however are removed separately with the greatest facility, so as to reveal, layer after layer, the various aspects of the parts-muscles, tendons, bones, \&c., being coloured after nature. To the different members are attached labels having referense to a synoptical table, bearing the name of the organ, and pointing out the extremity by which the displacement is effected. It afforded us great pleasure to observe the facility with which the disicetron might be accomplished, and in some parts the tout ensemble of the "region" was striking for fidelity of imitation, and, as far as we could observe, perfect accuracy of execution. As instances, the inguinal, abdominal, and cerrical regions, may be selected as excellent, whilst the view of the posterior parietes of the chest, the internal structure of the heart, kidney, \&cc., deserve similar commendation. The textures of the organs have been well imitated, so as indeed not to be mistaken; but in this respect, we think, a much nearer approach may be made to the bona-fide structures of the human body. Not a small advantage of this invention is the durability of the material of which the model is composed. Admitting at first of being moulded into any shape, it acquires the hardness of wood, so as to render the handling of the parts totally free from danger of injury; and the whole figure is constructed of the same composition. Some time was taken up in the exhibitions repeatedly eliciting the warm admiration of the members, which, in conclusion, was testified by an unanimous vote of thanks to Dr. Auzoux.

Dr. SIGMOND, therefore, in the name of the Society, returned thanks to the talented foreigner, who requested $\mathrm{Mr}$. Costello to express his acknowledgments.

The different pieces of the model require but a few minutes to put them together again, although the parts amount, we believe, to one hundred and twenty-nine.

Dr. Auzoux, in reply to a member, stated that the price of such a model was 3000 francs, or $125 l$.

Dr. BLICKE thought it incorrect to designate this invention as "new." He had seen the same kind of thing in wax many years ago in Germany and Italy; but (in answer to a query) such preparations were kept in glass cases, though they might be handled on particular request.

A Gentleman observed that he had also seen similar models in Bologna, but by no means so perfect, and in wax.

[Dr. Auzoux's model has just been purchased for the King's College. $\left.{ }^{1}\right]$

1 In THE LANCET of May 29th, 1909, p. 1551, an excerpt under the heading of "Looking Back" relating to other "anatomical and obstetric machinery" contained also a short reference praising the anatomical machines invented by M. Auzoux, further particulars of which are now given in the current number of THE LANCET select 